\title{
AN HLA-BASED BIDDING GAME WITH INTELLIGENT VIRTUAL PLAYER
}

\author{
Simaan AbouRizk \\ Stephen Hague \\ Yasser Mohamed \\ Aminah Robinson Fayek \\ University of Alberta \\ Hole School of Construction, Department of Civil and Environmental Engineering \\ Edmonton, Alberta, T6G 2R3, CANADA
}

\begin{abstract}
We present the development of a bidding game application designed to improve the decision making skills of students in estimating classes by allowing them to compete both against each other and against a virtual player developed using fuzzy logic concepts. The High Level Architecture (HLA) was used to develop a distributed model of the bidding process using different components (federates) that can cooperate in a large simulation model (federation). Each federate represents a role in the bidding process: general contractors, bank, virtual players, etc. These federates simulate bidding cycle activities and can each be run on separate computers. The Bidding Game is developed in the COnstruction SYnthetic Environment (COSYE), an integrated construction simulation platform; its development was used as part of a simulation course to teach the students how to develop collaborative simulation models and how to produce a final product as a team.
\end{abstract}

\section{INTRODUCTION}

Accurate estimation is an important part of our construction management students' skillsets. This paper describes a Bidding Game application, designed as a training tool to improve students' decision-making skills by allowing them to bid capital construction projects both against each other and against an intelligent virtual player. The game enhances users' knowledge of the bidding process in construction by employing a simulation model; users have an opportunity to explore bidding rules in a simple and competitive game environment.

Existing games, including CONSTRUCTO (Halpin and Woodhead 1970), SuperBid (AbouRizk 1993), and the AEC teaching environment (Fruchter and Krawinkler 1995), are no longer supported by current computing environments, and web-centric simulations (Scott et al. 2004), and Virtual Coach (Rojas and Mukherjee 2005), can be unstable and slow to load, so researchers are exploring new training tools for classroom demonstration. We present a solution using the High Level Architecture (HLA) to overcome existing limitations, deployed in the COnstruction SYnthetic Environment (COSYE). Using distributed simulation in this research helps developers to accelerate the development process of the model and simplifies complex systems by dividing the main model into several simulation components (federates) that can work together in a larger simulation system (federation). Federates can be of various types, but they create a common virtual environment and are reusable and interoperable in future similar simulation models.

In addition, while the game itself is a valuable pedagogical tool, the Bidding Game's development was also a pedagogical opportunity. The distributed nature of the COSYE simulation environment allowed the development students in an advanced construction simulation course to divide the problem 
among themselves and, working collaboratively, produce a final product as a team. Each group of students was responsible for a federate; the HLA standards and COSYE provided a framework and ensured interoperability.

\subsection{Construction Bidding Overview}

Traditional methods for construction bidding involve some form of competition between general contractors, in which price is usually the main factor for selecting among the contractors (Park et. al 1992). In this competitive environment, contractors' main concern is to find a bidding strategy which guarantees their success in bidding and maximizes their profits. The development of such strategies has sparked several research efforts; these studies mostly focus on two main concerns of general contractors in bidding: bid/no bid decision support systems and mark-up calculation methods (Egeman et al. 2008).

Contractors' decisions to bid or not to bid depend on several factors, such as: number of competitors, type of work, value of the project, location of the project, contractor's current workload, sub-contractors and their needs for work, bonding requirements and availability of other projects (Shash 1993). In the current game, students take the roles of general contractors and learn to consider these factors during their decision making process. Players discover that a high number of competitors decrease the chance of a successful bid; that the location of the project and availability of trade contractors in that area can decrease the chance of cost overrun; that profits will increase if players contract on projects similar to their past experiences; that trade contractors with high reliability ratings can decrease the cost and duration of the project, and that trade contractors' bid prices and reliability are key factors in the decision to bid for a project. Mark-up calculation is also an important phase of the bidding process, in which all the above criteria should be considered: players are responsible for estimating their overhead and setting their own mark-up rates The instructor can set certain parameters for each game to emphasize particular areas of construction bidding. As in the real world, profit will ultimately determine the winner. The bidding game strives to create a realistic environment; the many factors incorporated into its structure give players a more thorough understanding of the actual process.

Students can play against each other, but the Bidding Game also has a sophisticated virtual player option. The virtual player uses fuzzy logic concepts to evaluate projects and trade contractors and set markup, and ensures that even if most of the students are inexperienced, they will still get the benefit of competing against a knowledgeable opponent.

\subsection{High Level Architecture}

The HLA approach is a method for building complex virtual environments (federations) using distributed simulation technologies. It provides standards so that different developers can build the individual components (federates) of such environments while maintaining interoperability between them. The HLA standards also facilitate the reuse of the developed components as part of new federations. These standards consist of three main components: the HLA rules (IEEE 1516), the interface specifications (IEEE 1516.1), and the Object Model Template (OMT) (IEEE 1516.2).

The HLA rules ensure consistency and interoperability among federations and federates; the interface specifications define the functional interfaces between federates and the run-time infrastructure (RTI). The RTI is software that conforms to HLA specifications and provides software services such as synchronization, communication, and data exchange between federates to support an HLA-compliant simulation. The Object Model Template (OMT) supports communication between simulations; the Federation Object Model (FOM), a component of the OMT, defines certain standards for objects and their attributes and interactions within a federation.

\subsection{Construction Synthetic Environment (COSYE)}

The COSYE (AbouRizk et al. 2008) simulation environment is based on the HLA rules, and it consists of three major components (see Figure 1): 
1. COSYE RTI Server, a .NET implementation of IEEE standards 1516-2000.

2. Object Modeling Template (OMT) editor, used to define objects and their attributes.

3. COSYE framework, an application programming framework that allows developers to create federates and handles details of communication with the RTI. It integrates with code generated by the OMT editor and uses many of the visual programming features supported by Visual Studio. In addition, the framework supports both discrete-event and time-stepped federates.

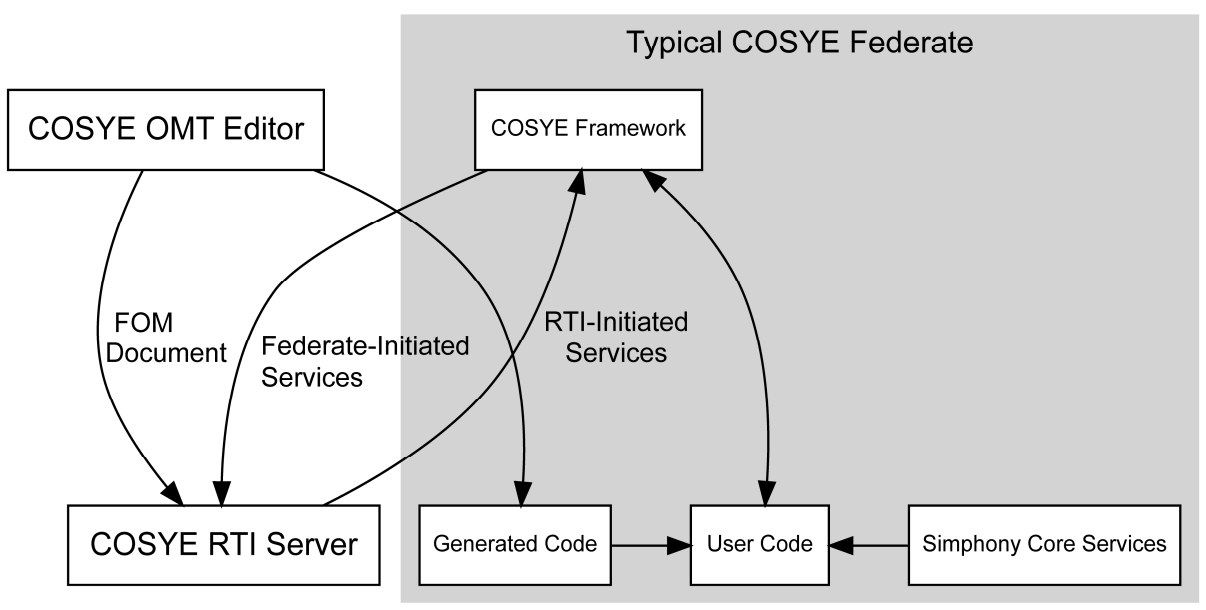

Figure 1: COSYE architecture with model federates.

\section{THE BIDDING GAME SIMULATION}

The current bidding game was developed in the COSYE environment through a collaborative effort involving twelve $\mathrm{PhD}$ students taking an advanced simulation graduate course. Different federates were developed by different groups of students and each group was responsible for handling different tasks in their federate. The strategies used to build these federates are similar to previous work related to the development of the bidding game SuperBid (AbouRizk 1993).

The key technical challenge was developing a Federation Object Model (FOM) that can be efficiently utilized by all developers on various federates, while fulfilling all federates' requirements, and representing all objects and interactions associated with the simulation model. The FOM development process consisted of five steps:

1. Building the bidding ontology to create a common understanding of bidding concepts among the federation developers.

2. Customizing the ontology to the Bidding Game.

3. Developing the first version of FOM based on the customized ontology.

4. Modifying the FOM according to groups' requirements.

5. Finalizing the FOM after several meetings and discussions. Figure 2 demonstrates the final FOM for the Bidding Game. 


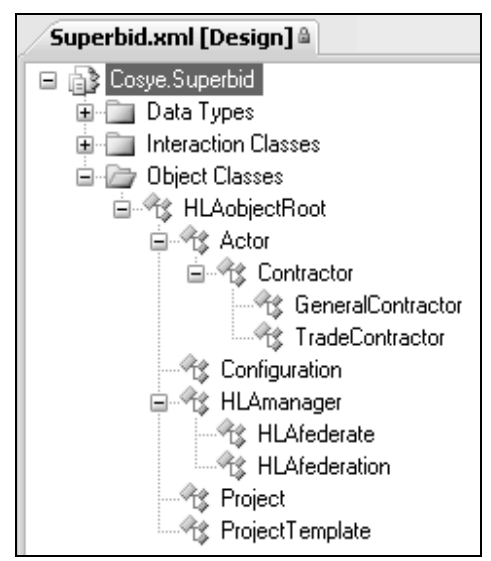

Figure 2: FOM for the Bidding Game.

Each group of developers developed federates based on the conceptual model using the final version of the FOM; the game's processes are based on SuperBid (AbouRizk 1993) but their implementation is quite different. The current version of the game was released in May 2008.

To start, the game randomly generates an initial amount of money for general contractors. In each period, some projects are released for tendering, and the controller keeps track of upcoming projects, submitted bid, performance of trade contractors and the transactions for general contractors. For each project, the size, type, location, duration and a randomly selected set of trade contractors are released, so players have enough information to decide whether to bid or not and which trade contractors and mark-up they choose to win the bid and maximize their profit (AbouRizk 1993). For any successful bid, the game updates the financial position of general contractors. At the end of the game, the general contractor with the highest value creation is the winner.

\subsection{Simulation of Bidding Game}

The model is composed of seven different simulation components (federates) that cooperate in a large simulation model, the Bidding Game federation (Figure 3). Each federate represents a different role in the bidding process and is responsible for simulating different activities in the bidding cycle, such as creating projects, awarding them, and tracking players' performance.

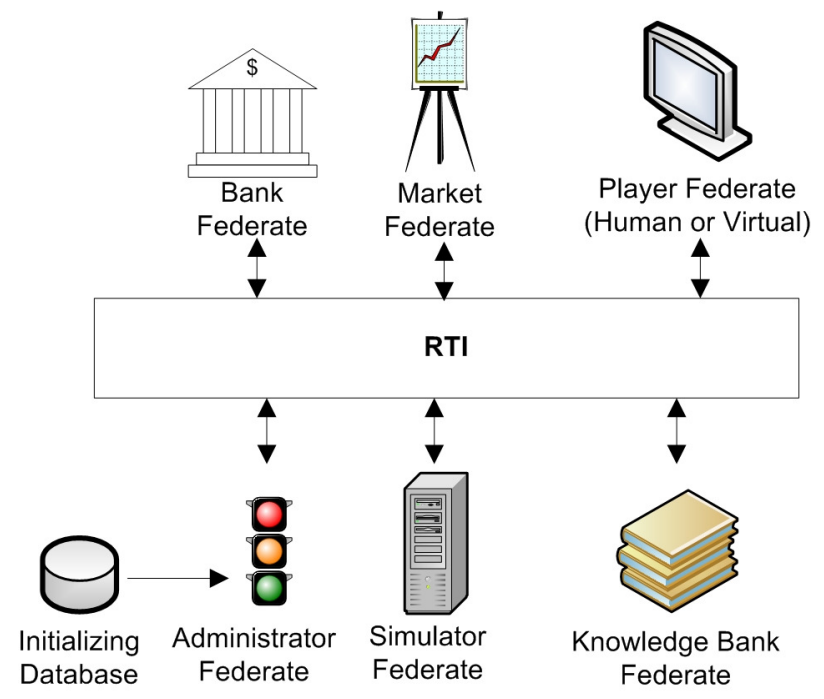

Figure 3: Bidding Game federation 
Modeling using HLA in the COSYE environment allows players to participate from different locations (anywhere internet access is available), and gives the developers the opportunity to continuously enhance the game to reflect real bidding situations in a more accurate way. Likewise, dividing the game into manageable federates helps students to learn exactly how each part affects the bidding process. For example, modeling the market separately can show how it can change the bid/no bid decision. The following sections describe the Bidding Game components and their tasks during the game; their interactions can be seen in Figure 4.

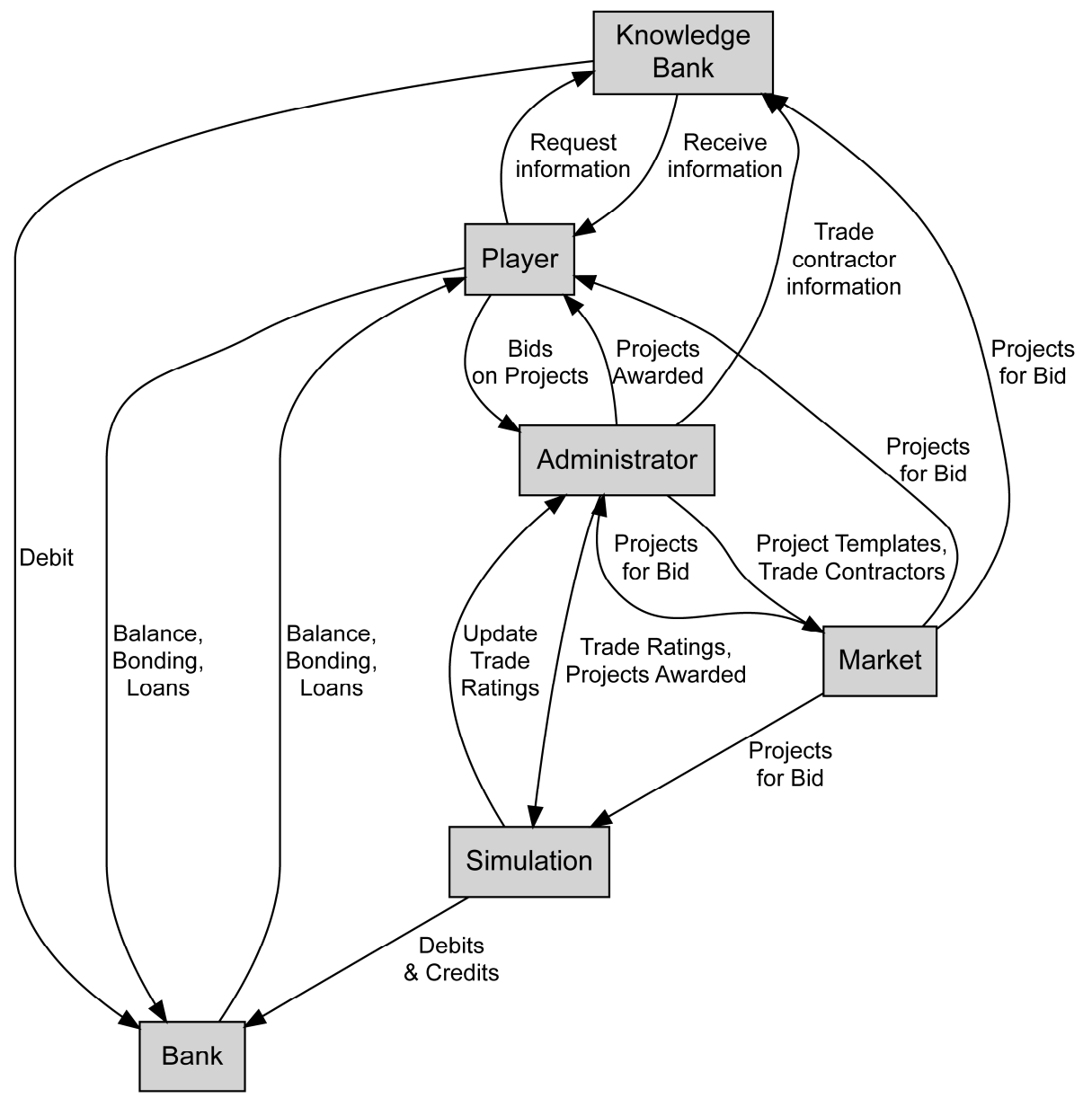

Figure 4: Overview of Bidding Game federates' interactions

\subsubsection{Administrator Federate}

The Administrator federate is a unique federate in the bidding game; it creates the game federation at the beginning of the game and terminates it at the end. During the game, it acts as a sort of clearinghouse, collecting bids, awarding projects, and advancing time, while showing an overview of the current state of the game. Figure 5 shows the execution flow of this federate.

This federation is responsible for the following tasks:

- Tracking and organizing the progress of the game

- Managing the various simulators, querying the databases, and maintaining the performance of each player, of the market, and of each project

- Configuring the key parameters (e.g. total number of periods, interest rates)

- Collecting bids and awarding projects to the lowest bidder 
- Assigning initial credit for general contractors

- Advancing the periods and showing the updated information for general contractors (GCs), projects, and awarded bids.

The Administrator federate is connected to two databases. The first database stores construction project data in the form of construction documents (category, range of size, range of unit price for each type of project). Players interact with the projects generated through this project template database. The second database includes trade contractor profiles (trade type, name, location, past performance, past experience, financial, resource and policies ratings). These databases are in XML format.

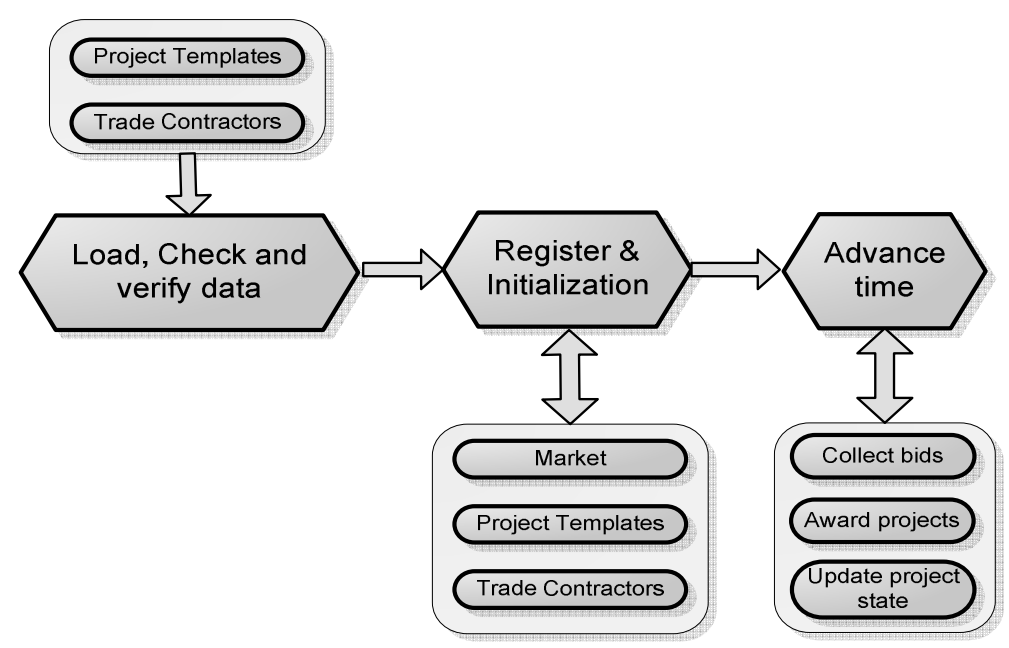

Figure 5: Execution flow of Administrator federate

\subsubsection{Simulator Federate}

The Simulator federate was based on the role of the owner in the construction phase of a project and keeps track of the progress and cost of the project. It calculates expenses and revenues and assesses penalties for late projects. This federate is responsible for the following tasks:

- Estimating project total cost according to the Project base cost generated by the Market federate

- Calculating the monthly progress of the project.

- Calculating general contractor's revenues and expenses on a monthly basis according to bid price and real cost of the project (project total cost divided by project base duration multiplying by different adjustment factors)

- Calculating the amount of penalty for late finish of the project and amount of the retainage at the end of the project

- Adjusting trade contractor ratings according to their previous month's performance

- Adjusting project monthly cost according to trade contractors' ratings and the distance between trade contractors' main office and project location.

To account for fluctuations in performance and cost, the federate uses a trade contractor rating system and a cost adjustment coefficient to estimate cost, based on a trade contractor's location and previous performance. To obtain the adjustment coefficient, it generates a random number between the adjustment ranges shown in Table 1, based on the trade contractor's rating. 
New rating $=$ Existing rating - adjustment coefficient

Table 1: Trade contractor rating system and adjusting coefficient

\begin{tabular}{cc}
\hline \multicolumn{2}{c}{ Rating system } \\
\hline Rating & assume boundaries \\
Excellent & $80-100 \%$ \\
Good & $60-80 \%$ \\
Average & $40-60 \%$ \\
Fair & $20-40 \%$ \\
Poor & $0-20 \%$ \\
\hline
\end{tabular}

\begin{tabular}{cc}
\hline Rating & Adjustment Coefficient Range \\
\hline$>60 \%$ & $-10 \%$ to $3 \%$ \\
$30-60 \%$ & $0 \%$ to $10 \%$ \\
$0-30 \%$ & $8 \%$ to $20 \%$ \\
\hline
\end{tabular}

The first step in cost adjustment uses an adjustment coefficient based on the trade contractor's rating and the trade contractor's portion, which is drawn from a database of project types:

Adjustment Factor $_{1}=$ project base cost $\times$ adjustment coefficient $\times$ subcontractor's portion

In the second step, cost adjustment is based on the trade contractor's location. First, the distance between the selected trade contractor and the project is calculated, and then, as in the above method, the cost is adjusted using the adjustment coefficient in Table 2. It is assumed that projects, trade contractors, and general contractors are located in a (4 unit $\times 4$ unit) square area.

Adjustment Factor $_{2}=$ project base $\cos \mathrm{x} \times$ subcontractor's portion $\times$ adjustment coefficient cost

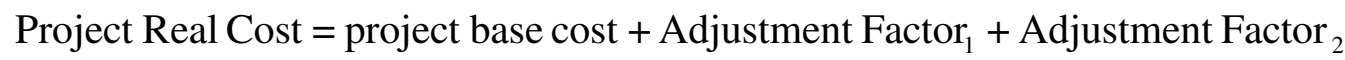

Table 2: Cost adjusting coefficient according to trade contractor location

\begin{tabular}{cc}
\hline Trade contractor Distance from Project Site & Adjustment Coefficient \\
\hline$>3$ & $8 \%$ to $20 \%$ \\
$1.5-3$ & $0 \%$ to $10 \%$ \\
$0-1.5$ & $-10 \%$ to $3 \%$ \\
\hline
\end{tabular}

\subsubsection{Market Federate}

The Market federate generates market conditions: how many and what kind of projects are available for bid at any one time, as well as what trade contractors will bid for each project. It can generate market conditions either randomly using standard probabilistic techniques (Figure 6), or based on actual data the "Canadian Construction Industry Forecast" prepared by the Construction Sector Council (CSC). The trade contractor bid prices can be set using a formula to determine parameters for bid price distribution, or using past performance indices to determine bid price distribution parameters. The Market federate interface, where the user can choose the type of market generation and trade contractor bid price distribution parameter determination, is shown in Figure 7. 


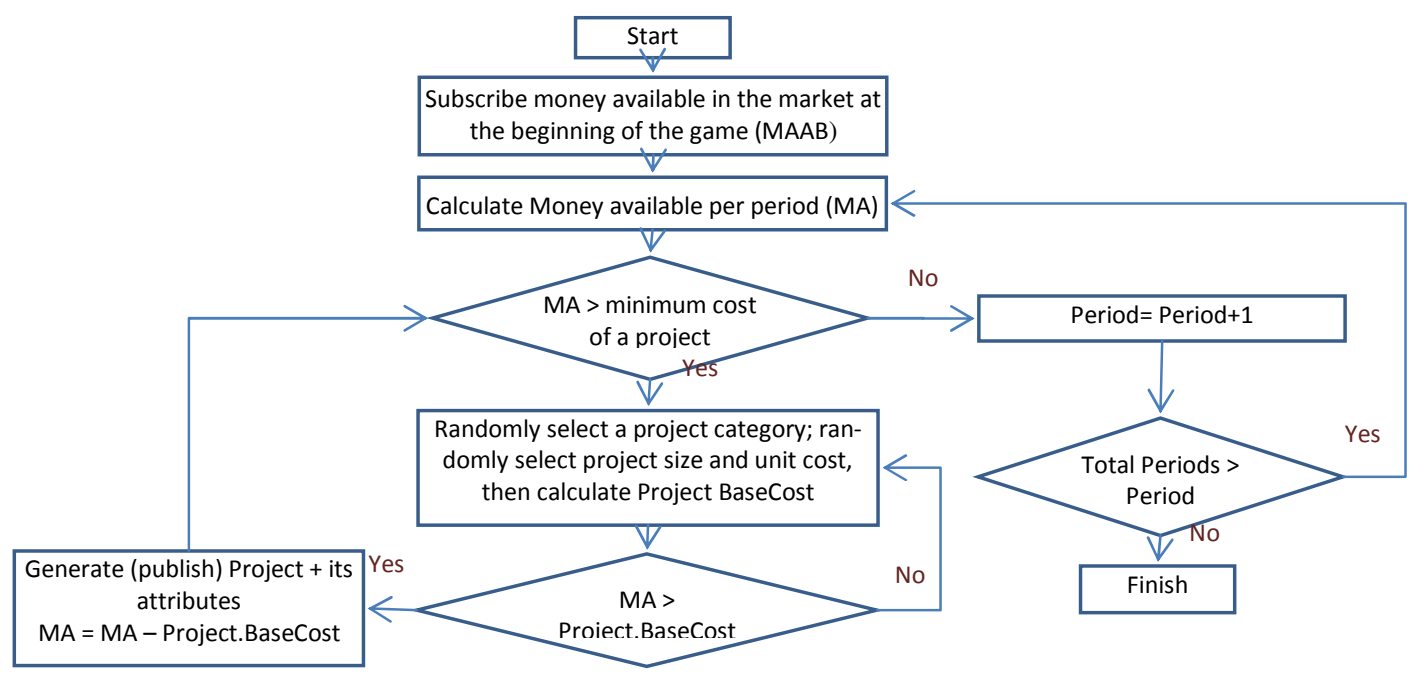

Figure 6: Randomly generating projects

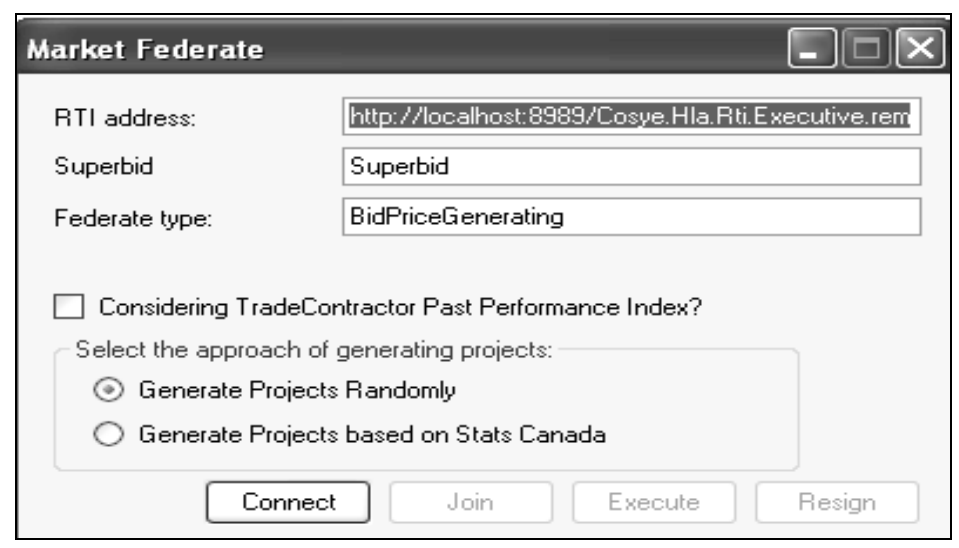

Figure 7: Market federate

\subsubsection{Bank Federate}

The Bank federate supports all required financial services of the game, including maintaining players' accounts, granting loans, issuing bonds, and charging project costs. The federate is structured around these four categories:

1. Account balance - opening an account for the winning contractor, calculating interest and account balance after each account transaction.

2. Loan services - calculating financial credit limit after each account transaction, granting loans to players according to their credit limits and their requests, receiving loan repayments, and calculating loan interest periodically.

3. Bond services - calculating the bonding limit after each account transaction, validating players' bonding limit in the bidding process, issuing bonds for players, charging bond fees to players

4. Project cost services - charging bid preparation costs to the bidders 


\section{AbouRizk, Hague, Mohamed, and Fayek}

\subsubsection{Knowledge Bank Federate}

The Knowledge Bank federate provides players with information about trade contractors and future projects - for a price. In the initiation phase, the Market federate supplies a small set of information about the projects along with information about the chosen trade contractors for each project; this information encourages the players to analyze the bidding competition and come up with better strategies. The Knowledge Bank federate expands on that information, allowing players to buy reports on trade contractors or projects that will be available in the following period. The trade contractor report includes ratings for each trade contractors' finances, past experience or performance, policies, and resources; the future projects report includes the title, category, and size of future projects. The Market federate sets a price for each report, depending on the current market conditions.

\subsubsection{Human and Virtual Player Federate}

Players interact with the game by submitting tenders for a particular project, making decisions during the game related to managing projects they were awarded, managing the financial state of their company (loans, bonds, etc.), and responding to changes during the progress of their work. The Player federate allows all users to compete using an identical user interface on different computers; the computers can be anywhere with a network connection.

There are two types of players in this game: human players, who interact with the game externally, and "virtual players", which were built by incorporating fuzzy logic concepts into the distributed simulation program (Shaheen et al. 2009). The virtual player uses those concepts to evaluate subcontractors and projects, estimate mark-up, and suggest bids. A human player can choose to play with the "advice" of a virtual player and let the program decide to bid on a project and produce a mark-up. The The virtual player then uses fuzzy expert systems to evaluate trade contractors and projects, estimate mark-up, and suggest bids.

The virtual player is structured as two different intelligent modules: one is the trade contractors' evaluation model, and the other is the mark-up estimation model. Both modules use fuzzy logic concepts to generate a list of preferred subcontractors and then determine the mark-up (El-Barkouky and Abdelgawad 2008). The virtual player has access to the same information as the human player, and uses an independent fuzzy expert system, which has been created by experts in construction bidding to interpret the trade contractors' ratings and the project descriptions and determine the suggested markup.

The trade contractor evaluation module receives information from the knowledge bank regarding the trade contractors for a given project and the bids submitted by those trade contractors. The information is in the form of ratings in five separate categories for each contractor (Performance, Experience, Financial, Policies, and Resources). The ratings are linguistic terms, "Poor," "Fair," "Average," etc; this is the same as what the human players see. The evaluation module transforms these ratings into fuzzy numbers (e.g., the triplet for "Poor" is $0,0,0.2$ ) and uses a weighting system, developed through consultation with bidding experts, to weight each category appropriately. The ratings matrix is multiplied by the weighting matrix, and the final fuzzy matrix is then normalized and transformed into crisp values; the model then selects the trade contractor with the highest crisp value.

After the best trade contractor is determined, the markup module evaluates the risk and uncertainty of a given project using a fuzzy inference system designed under the fuzzyTECH ${ }^{\circledR}$ environment, which is integrated with the Bidding Game RTI. Five attributes generated by the market federate, City Index, Site Index, Penalty Per Period, Project Size, and Work Availability, were assigned appropriate membership functions (e.g., City Index can be Fair, Poor, Good, Average, or Excellent; Project Size has five membership functions ranging from 2,000 to $1,000,000 \mathrm{ft}^{2}$ ), and the potential markup was assigned six fuzzy numbers (M1, M2, .., M6) representing the percentage markup. About 800 rules for determining markup were obtained and coded in the fuzzyTECH ${ }^{\circledR}$ environment, which uses these rules to assign the project a markup level, such as M5, which is then defuzzified to a markup percentage. The virtual player 
uses the selected trade contractors' bids and the markup percentage to generate a bid. The Bidding Game is intended to be used in a classroom setting, so the addition of a virtual player keeps the other players alert.

The user interface for players gives an overview of information about the current state of the game (Figure 8), such as all the projects generated by the Market federate, selected trade contractors for each project, and the awarded project information. As previously mentioned, a player can also buy trade contractors' ratings and projections of the next period's projects. The virtual player has no advantage in this respect and is also required to purchase this information.

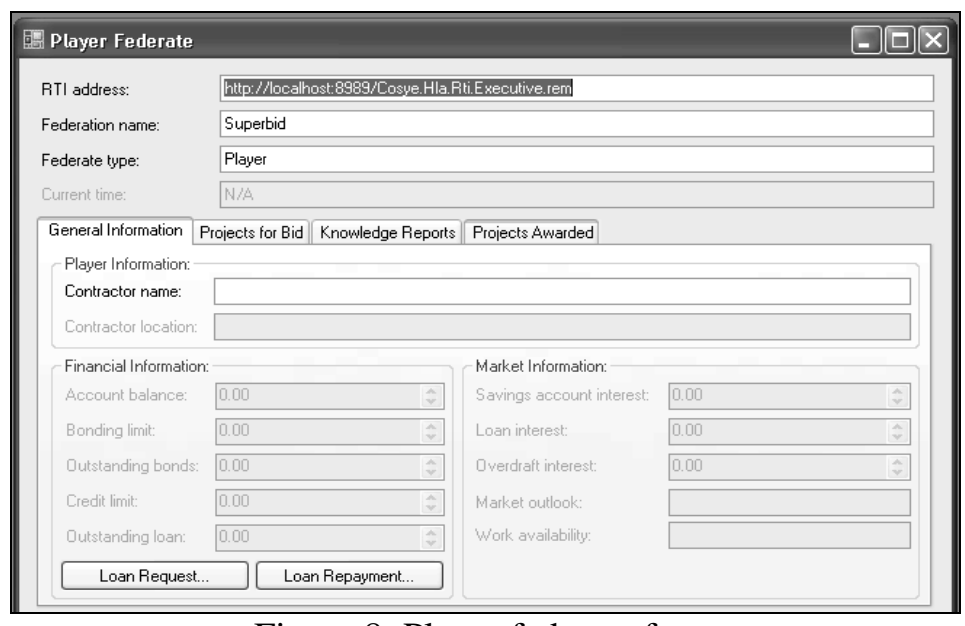

Figure 8: Player federate form

\section{USE IN THE CLASSROOM}

\subsection{Bidding Game Use}

Construction bidding is competitive, and the bidding process involves numerous factors, variables, and parameters. The contractor must solicit bids from trade contractors, estimate the direct cost of the project including direct overhead, and add a markup to cover contingencies, other overhead, and a suitable profit margin. The general objectives are to obtain a high enough rate of return to remain competitive, to maintain expertise by sustaining a certain level of operation, and to perform at a level (financial, safety, quality, integrity, etc.) adequate to insure proper bonding on future projects. Bidding strategies are numerous and depend on a company's individual goals and many other variables. However, if a contractor accurately estimates project cost, and all other factors remain unchanged, several characteristics of bidding competitions can be summarized:

- As the number of bidders increases, the chances of winning a project decrease

- As the markup increases, the chances of winning a project decrease

- Past experience with similar projects generally results in better project execution, and therefore more profit and success

- The quality of trade contractors will have an impact on performance

- Careful monitoring of major competitors can provide a crucial edge

- Uncertainty factors in estimation and actual project execution are a fact of life and must be accounted for

The Bidding Game was designed to highlight these characteristics; its objectives are to 1) teach the player about the various factors to consider during bidding; 2) enable the player to observe and experience 


\section{AbouRizk, Hague, Mohamed, and Fayek}

the bidding process, including forecasting, financial planning, decision making under uncertainty, and random factors; 3 ) provide a medium for experimenting with different bidding strategies to achieve a desired objective, and 4) highlight the importance of financial book-keeping fundamentals.

In a classroom setting, the Bidding Game can be used to demonstrate these concepts; the administrator federate, in the hands of a skilled instructor, allows the settings to be fine-tuned to emphasize, for example, that unreliable trade contractors can leach profit from a project, or the effect of market conditions on bidding. For more sophisticated students, the Bidding Game allows experimentation with different bidding strategies and the opportunity to acquire experience with balancing loans, bonding, and market projections. The virtual player allows students to test themselves against a bidding expert. Hands-on experience with construction bidding is not easy to obtain; the Bidding Game can be a valuable tool when used appropriately.

\subsection{Bidding Game Development}

The first generation of this game was originally developed to allow students to learn about bidding practice in an interactive and fun environment. The original implementation depended on a database backend for facilitating all interactions. The HLA implementation described in this paper was mainly approached as a training exercise for graduate students learning about distributed simulation and HLA for the first time. The main objective was to provide them with a problem that is challenging enough for them to learn and appreciate the capabilities of a distributed simulation approach, but at the same time not overwhelmingly difficult to be modeled and implemented within the limited time of a graduate course.

Students were divided into groups of 1 to 3 and assigned the development of one federate in the federation. Assignment of the federates took into consideration the student's research interests to capitalize on their individual expertise. For example, student working in the area of fuzzy logic were assigned to develop the virtual player federate, and students working in areas related to knowledge representation were assigned to develop the knowledge bank federate.

Challenges arose in the early development stages of the federation. These challenges were mainly related to work coordination issues. For example, agreement on FOM structure and scoping the work of each federate proved to be more difficult than anticipated before starting the exercise. It required a number of brainstorming and discussion meetings to reach a common agreement on the role of each federate in the federation.

Most of the students completing the exercise have already completed a course in traditional discrete event simulation techniques. However, the broader view that the distributed simulation approach provides proved to be a challenge for many of them as they had to think in a more generic way beyond the constructs of discrete event and process interaction simulation environments.

After completion of several cycles of developments in the class, it was realized that game provided a very successful medium for the student to learn and explore the capabilities of the distributed simulation framework. It was also very rewarding for them to be able to collaboratively develop and execute the simulation game especially when they realized that the game play is serious enough to beat most of them.

\section{CONCLUSION}

This paper describes the development and classroom use of a bidding game using HLA, which allowed collaborative development and aids in the reusability of components for future similar models. Bidding games are a time-honored way to sharpen construction management students' estimating skills; the addition of a fuzzy-logic-based virtual player means that players will always be competing against at least one expert bidder, who has access to the same information but interprets it with the skill of an experienced estimator. The model is created based on the real-world bidding practices of the construction industry to allow users to examine different strategies in this existing game environment, and can incorporate realworld market statistics to allow students to practice bidding in the kind of environment they will experience upon entering the workforce. Future development will involve expanding the game using agent- 
based simulation and game theory to model human and virtual players and their interactions; these interactions will allow the game to even more closely approximate real-world conditions.

\section{ACKNOWLEDGMENTS}

The authors would like to thank the academic and research staff of the Hole School of Engineering at the University of Alberta and the PhD students who contributed to this research: Mohamed Abdelgawad, Mohammed Al-Battaineh, Amin Alvanchi, Reza Azimi, Mohamed El-Barkouky, Amr El-Nimr, Di Hu, Elmira Moghani, Farzaneh Saba, Naeemeh Sadeghi, Hosein Taghaddos, and Hua Xie. We sincerely appreciate their dedicated support and contribution to this research. This study was supported by the National Science and Engineering Research Council (NSERC) Industrial Research Chair in Construction Engineering and Management. Without this funding, this research would not have been possible.

\section{REFERENCES}

AbouRizk, S. 1993. A stochastic simulation of construction bidding and project management. Microcomputers in Civil Engineering, Elsevier Science Publisher Ltd, Vol. 8, pp. 343-353.

AbouRizk S. M., and F. A. Robinson 2008. Synthetic environments for construction planning and control. NSERC IRC Renewal application 2007-2011, pp. 11-15

$\mathrm{Au}, \mathrm{T} ., \mathrm{R}$. L. Bostleman, and E. Parti. 1969. Construction management game-deterministic model. ASCE Journal of Construction Division, Vol. 95, pp. 25-38.

Egemen, M., and A. Mohamed. 2008. SCBMD: A knowledge-based system software for strategically correct bid/no bid and mark-up size decisions. Automation in Construction, Vol. 17, pp. 864-872.

Fruchter, R., and H. Krawinkler, 1995. A/E/C teamwork. Proceedings of the Second Congress on Computing in Civil Engineering, Atlanta, June 1996, pp. 441- 448

El-Barkouky, M., and M. Abdelgawad. 2008. Player federate: Part II-virtual player module, internal report for Advanced Simulation course, pp. 3-14

Halpin, D.W., and R.W. Woodhead. 1970. CONSTRUCTO - A computerized construction management game. Construction Research Series, No.14, Department of Civil Engineering, University of Illinois, Urbana, IL.

Park, W.R. and W.B. Chapin. 1992. Construction Bidding: Pricing for Profit. John Wiley \& Sons, New York

Rojas, E. and A. Mukherjee. 2005. A general purpose situational simulations environment for construction education. Journal of Construction Engineering and Management, ASCE, 131 (3), 319-329.

Scott, D., M. Mawdesley, and S. Al-Jibouri. 2004. The use and efficacy of a simulation model for teaching project control in construction. First International Conference on world of construction project management, Toronto, May.

Shaheen, A., A.R. Fayek, and S.M. AbouRizk. 2009. Methodology for integrating fuzzy expert systems and discrete event simulation in construction engineering. Canadian Journal of Civil Engineering, 36: 1478-1490.

Shash, M. 1993. Factors considered in tendering decisions by top UK contractors. Construction management and economics, March 1993, pp 111-118

\section{AUTHOR BIOGRAPHIES}

SIMAAN M. ABOURIZK holds an NSERC Senior Industrial Research Chair in Construction Engineering and Management at the Department of Civil and Environmental Engineering, University of Alberta, where he is a Professor in the Hole School of Construction. He received the ASCE Peurifoy Construction Research Award in 2008. His email address is <abourizk@ualberta.ca>. 
YASSER MOHAMED is an Assistant Professor in the Hole School of Construction at the Department of Civil and Environmental Engineering, University of Alberta.

STEPHEN HAGUE is the Senior Programmer for the Hole School of Construction, Department of Civil and Environmental Engineering, University of Alberta.

AMINAH ROBINSON FAYEK is the Ledcor Professor in Construction Engineering in the Hole School of Construction and holds an NSERC Associate Industrial Research Chair in Construction Engineering and Management at the Department of Civil and Environmental Engineering, University of Alberta. 